\title{
QUALITATIVE RESEARCH IN CARDIOLOGY: TO BE VIRTUOUS OR FAIL
}

\author{
Taratukhin E. O.
}

Qualitative research is an aristocracy among research methods. Being capable to reach the understanding of events so deep and individual that unattainable for quantification, it requires the same level of capacities from an investigator. In cardiology, biomedical in her origins, novel patient-centered paradigm demands new understanding of the relevance: the relation of scientific findings with clinical application, which, from this point of view, involves the person's biopsychocultural wholeness. Essential controversy originates from the positivistic impossibility of generalization of qualitative findings, and their broadly assumed fallibility. The results of a study depend on the personality of researcher: the interpreter. If such personality, being invited to another person's realm, is not enough virtuous, the results of research will be vain. This article focuses on the need and possibility of implementation qualitative research to cardiovascular science on the way to patientcentered paradigm of healthcare. Some argumentation provided, as some literary review of recent qualitative trials in cardiovascular field.
Key words: personalized medicine, patient-centered care, empathy, interview, psychological assessment, psychosomatics, biopsychosocial, philosophy of medicine.

N.I. Pirogov Russian National Research Medical University (RNRMU), Moscow, Russia.

Corresponding author. Taratukhin E. O. MD, PhD, M.A., associate professor at Department of Internal Medicine and in University Clinic of Internal Diseases, cardio03@list.ru.

Received March 15, 2016

Revision received March 17, 2016

Accepted March 24, 2016.

\section{КАЧЕСТВЕННЫЕ ИССЛЕДОВАНИЯ В КАРДИОЛОГИИ: ВИРТУОЗНО ИЛИ НИКАК}

\author{
Таратухин Е. O.
}

ках на пути к пациент-центрированной парадигме здравоохранения. Представлена аргументация и литературный обзор последних качественных исследований в кардиологии.

Российский кардиологический журнал 2016, 4 (132), Англ.: 195-197 http://dx.doi.org/10.15829/1560-4071-2016-4-eng-195-197

Ключевые слова: персонализированная медицина, пациент-центрированная помощь, эмпатия, интервью, психологическая оценка, психосоматика, биопсихосоциальный, философия медицины.

ГБОУ ВПО Российский национальный исследовательский медицинский университет им. Н.И. Пирогова Минздрава России, Москва, Россия

Biomedical point of view takes the body as sophisticated biochemical laboratory, hosts of molecular interactions that, originating from DNA, consequently present as ourselves. However, such complexity is even not sufficient, as there is plenty of feedback interactions. Epigenetics, psychoimmunology and other modern interdisciplinary fields show us that interaction happens in opposite directions together: genes determine phenotype, and living world of the phenotype influences the genes to be expressed and even transferred to descendants.

Such point of view makes modern medicine a medicine of human wholeness that shall include everything from the very genes to personality in its psychosocial complexity. And cardiology - one of the key players among non-communicable diseases managers - is to change on the way towards becoming a real cure for her patients. 
European Society of Cardiology in their Position Paper have put it, that not only modern technologies will drive personalized medicine, but patients must be taken in all their cultural background, including thoughts and wishes, cultural aspects (as e.g. sex vs gender), relationships, experiences, - i.e. personality. Published in 2014, this paper was issued consequently after the papers of WHO related to Peoples Centered Care paradigm. Tokyo conference (2007) on the Reorientation of Healthcare systems in 21st Century, was concluded with the issuance of Technical Papers for People-Centered Care [1, 2]. Key points of this paradigm are the ways in which individuals, families and communities play roles in promoting health. Among these ways are understanding of the disease and factors influencing health, selection of the most appropriate treatments, monitoring symptoms and treatment effects, adopting healthy behaviors, etc. Such conditions are definitely not biomedical, but psychological and psychosocial. Hence the question raises how to make non-physicians to be able to fulfill these, and how to involve them - their selves fully, not formally, into the processes of healthcare.

Every physician working with a patient as with human, not moving body, will not refuse that the personality is a term that is intuitively clear, however almost impossible to define. Personality is based on embodied part, with psychological traits and cultural relationships. The latter two are not studied by medical science, and are the subjects of either psychological range of approaches, or the humanities. Yet there is an opposite flow of cultural influences towards the body, that are mediated by psychological phenomena. Personality, having been constituted by biology that blossoms in culture, is being continuously changed by culture influencing biology.

To study, to assess biology, scientists have experimental and observational methods. They collect cases; sameness of the studied trait provides information about the law of nature and grounds consequent influences on biology to change it in the way personality wants to.

However, neither culture, nor pure psychology, can be studied experimentally and quantitatively. There is always a gap for symbolization, interpretation. Such specifics require another sort of insight.

Qualitative methods are the methods of social sciences. Even there such approaches are a kind of marginal, being condemned for lack of evidence, for impossibility to provide universal, generalizable data. This is so if to take paradigm of total interchangeability of investigators. That is, if for quantitative approaches there is no need for selection of an exact doer, when the tool is well-prepared and complete (i.e., questionnaires), qualitative require specific skills and capacities, even virtues, to merge deeper into the covert details of another human world of experience. Moreover, data from purely qualitative methods cannot be statistically proved. Only operationalization of concepts might be a mechanism for more or less quantification. But the latter is out of the essence of qualitative research.
In cardiology, a biomedical field in its gist, application of qualitative methods is challenging, and the path to introduce data obtained with these methods into clinical practice, is thorny.

Nevertheless, qualitative research enters cardiology. And it is up to researches, whether to fulfill demands of clinical practice or to fail.

One of the points that can be applicable for this sort of data acquisition, is a study of perspectives. Thus, Pals et al. (2015) report on the study of patient and physician perspectives on new technologies in clinical practice. The investigators were interested whether the new technologies (e.g., technology to detect cardiovascular autonomic neuropathy in diabetes) in cardiovascular practice are accepted by patients, and physicians as well. Study relied on the data from observations of medical consultations, on interviews with patients and with physicians. Findings showed quite serious misunderstandings in application of the new technology by patients, as by physicians. Conclusions the authors made in the study, were that more information should be provided to patients and dialogue based approach is needed when communicating test results [3].

Another study was done by Lambert-Kerzner et al. (2015) concerning the perspectives of patients on factors of adherence to medical regimens following acute coronary syndrome. They start from the issue of poor adherence of patients that leads to an increased risk of re-hospitalization and higher mortality. In-depth interviews were conducted with patients after acute coronary syndrome. In these interviews patients pointed that some factor might improve their adherence, such as frequent interactions with providers, reminder calls, social support, adherence routines, and last but not least the positive attitudes toward acute coronary event. It was important for patients to be active participants in health care decision making. The concepts that emerge according to the data obtained, were, as concluded by the authors: respectful collaborative communication, training of healthcare providers to elicit and acknowledge patients' views [4].

Patients perspectives on pharmacists' prescribing were the object of McCann et al. (2015) study. Researchers used case studies approach with focus groups for three contexts of prescription: hypertension, diabetes, anticoagulation. Analysis revealed one overarching theme: team approach to patient care; there was also lack of awareness despite general positive attitude towards pharmacist prescribing [5]. Virdee et al. (2015) studied patients' views on polypill for cardiovascular risk. The method was semi-structured interviews with following qualitative description. The results showed the concepts of concern about appropriateness of polypill despite benefits, skepticism about polypill as "blanket" approach. Authors conclude that in population-wide offering of polypill there is need for patients education [6].

These studies demonstrate some crucial properties of qualitative research. On the one hand, the data obtained in 
these studies could be gathered with properly designed questionnaires. On the other, some shades of the senses are acquirable only from deeper interpersonal exchange, such as in-depth interview. The difference here rests upon the aim: either to find out a kind of pattern or to define the way of experiencing.

However, there is still a lot of further issues. Sticking childish question "What is?.." one could ask "What is a positive attitude?", "What is a real participation in decision making, as patients are not physicians?", "What is it practically to elicit and acknowledge the views?", "What do the concerns and doubts consist of?". These are the matter of deep understanding and interpretation. Even more, as Susan Sontag stated in her famous "Against interpretation", we need an "erotics of art" in place of hermeneutics. Can one draw from this statement, that neither re-symbolization nor explanation are needed to reach perfect understanding of a cultural event, but experiencing?

What are, if not experiencing, patient's issues on their condition, health, life quality, understanding of their disease and decision making? To evidence personal experiences for clinical practice or policy making, qualitative data, lacking statistical proof, must fulfill some other criteria of trustworthiness. In the Oxford Handbook of Qualitative Research (ed. by Patricia Leavy), one can find such criteria. These include the eight (by Tracy, 2010): worthy topic, rich rigor, sincerity, credibility, resonance, significant contribution, ethics, meaningful coherence (cited from Cho\&Trent, 2014), [7]. Are these criteria applicable for cardiology-related qualitative research?

The answer is yet to be given. However, if to look closer, one might say that the role the results of research would play in clinical practice, does determine value. Definition of "the role", as I see it, depends upon the worth of biopsychocultural nature of the ill person for managing process. And if physician works with personality, but not just somatic disorder, the answer is definitely "yes".

Astin et al. (2014) report on the synthesis of qualitative research for lifestyle change to reduce coronary risk. They point that few people fully succeed in daily activities improving lifestyle. After comprehensive review of 27

\section{References}

1. Kirchof P, Sipido KR, Cowie MR, et al. The continuum of personalized cardiovascular medicine: a position paper of the European Society of Cardiology. Eur Heart J, 2014; doi:10.1093/eurheartj/ehu312.

2. People-Centred Health Care. Technical Papers. International Symposium on the Peoplecentred Health Care. WHO publications, 2008.

3. Pals RAS, Hansen UM, Johansen $\mathrm{CB}$, et al. Making sense of a new technology in clinical practice: a qualitative study of patient and physician perspectives. BMC Health Services, 2015; doi:10.1186/s12913-015-1071-1.

4. Lambert-Kerzner A, Havranek EP, Plomondon ME, et al. Perspectives of patients on factors relating to adherence to post-acute coronary syndrome medical regimens. Pat Pref and Adher, 2015; 9: 1053-9. studies with over five hundred participants the authors found common elements as transformation of self-identity; reassessment of "past, present and future"; urge to get back to "normal"; defining lifestyle change as part of wider "life" change; experiencing life as "worth living". Conclusion remarks include an important concept of a person-centered model of the explanation how lifestyle change is situated within "wider" life changes. Authors synthetize a scheme of Lifestyle Change Process. They also remark that there is need for health professionals who are able to provide support for people experiencing grief and that recognition of lifestyle necessity by physicians is not obviously shared by patients and their families. The latter can be a source of tension, and it is worthy to have skills or even aptitudes for person-centered care that aligns with both closely linked physical and psychological dimensions [8].

This study, a meta-analysis, shows important issues on the position and applicability of qualitative research in the field of cardiovascular science and practice. As soon as we expect some transformations of lifestyle, we have to remember that "life style" includes the word "style" from the humanities and the word "life" that is totally interdisciplinary. To achieve such aim as behavior (a term from psychology; part of the "life style") shift, we need to utilize instruments of scientific fields that deal with the style, i.e. symbolic, interpretative, cultural matters. Such matters are unreachable for quantification and to study and apply this, researcher must deal with the methods from the studies of culture, but implemented to living people. This is a challenge for both psychological and social sciences. However, medicine oughts to include them, because it is in her essence.

To be relevant for modification of treatment approaches in cardiology, with the specific aims for global personal life changes (not simply describe and analyze), qualitative research must be extremely virtuous, thorough, ethic and have intrinsic capacities enough to become an instrument for clinical utilization. Requirements for research in this sense are the requirements to researchers, who must be really extraordinary skillful to correctly obtain and process information from human for humanity. Metaphorically, these are the properties of the noble.

5 McCann LM, Haughey SL, Parsons C, et al. A patient perspective of pharmacist prescibing: 'crossing the specialisms - crossing the illnesses'. Helath Expect, 2015; 18(1): 58-68.

6. Virdee SK, Greenfield SM, Fletcher K, et al. Patients' views about taking a polypill to manage cardiovascular risk: a qualitative study in primary care. Brit $\mathrm{J}$ of Gener Practice, 2015; 65(636): e447-e453.

7. Cho J, Trent A. Evaluating Qualitative Research / The Oxford Handbook of Qualitative Research Leavy P. (ed.). - Oxford University Press, 2014; 677-95.

8. Astin F, Horrocks J, Closs SJ. Managing lifestyle change to reduce coronary risk: a synthesis of qualitative research on peoples' experiences. BMC Cardiovasc Disord, 2014; 14(1), art. No 96. 